\title{
Entre o Direito e a Literatura: uma análise da jurisdição atual e do papel do juiz no tratamento dos conflitos ${ }^{1}$
}

Fabiana Marion Spengler ${ }^{2}$

Resumo: Levando em consideração as crises pelas quais passa o Poder Judiciário e as modificações do papel atribuído ao juiz o presente texto tem por objetivo discutir o sistema Judiciário enquanto meio legitimado a punir condutas racionalizando a violência. Além disso, abordará os contornos da função decisória atribuída aos magistrados. Para cumprir tal intento utilizou-se das intersecções entre direito e literatura, especialmente discutindo a comédia "As Vespas" de Aristófanes. Desse modo, o texto primeiramente delineou o monopólio estatal da força por parte do Estado enquanto meio legítimo de punir a violência e de dizer o direito. Posteriormente abordou a jurisdição e suas crises bem como as dificuldades de implantar uma outra cultura que tenha por prioridade as formas alternativas de resolução de conflitos tais como a mediação, a conciliação e a arbitragem.

Palavras-chave: Jurisdição. Literatura. Mediação.

\begin{abstract}
Considering the crises Judiciary current undergoes and the changes to the role ascribed to judges, this text aims to discuss the judicial system legitimized as a means to punish conduct rationalizing violence. Furthermore, it will engage the contours of the decision-making role assigned to judges. To fulfill this purpose, we used the intersections between law and literature, especially discussing the comedy "The Wasps" by Aristophanes. Thus, the text first outlined the State monopoly of force by the State as a legitimate means of punishing violence and speaking the law. Subsequently, we addressed the court and its crises and the difficulties of deploying another culture that has priority for the alternative forms of dispute resolution such as mediation, conciliation and arbitration.
\end{abstract}

Keywords: Jurisdiction. Literature. Mediation.

1 O presente texto foi elaborado a partir de pesquisa realizada junto ao projeto intitulado "Mediação de conflitos para uma justiça rápida e eficaz" financiado pelo CNPq (Edital Universal 2009 - processo 470795/2009-3) e pela FAPERGS (Edital Recém-Doutor 03/2009, processo 0901814) coordenado pela autora.

2 Advogada. Doutora em Direito pelo programa de Pós-Graduação stricto sensu da Universidade do Vale do Rio dos Sinos (UNISINOS), mestre em Desenvolvimento Regional pela Universidade de Santa Cruz do Sul (UNISC). Professora dos cursos de Graduação e Pós-Graduação da Universidade de Santa Cruz do Sul (UNISC). Coordenadora do Grupo de Estudos "Políticas Públicas no Tratamento dos Conflitos" vinculado ao CNPq. E-mail: fabiana@unisc.com.br.

Recebido em: 06/12/2010.

Revisado em: 11/01/2011.

Aprovado em: 29/03/2011. 


\section{Introdução}

Nunca se discutiu tanto acerca das crises $^{3}$ da jurisdição como hodiernamente. Embora exista o (re)conhecimento de que o Judiciário enquanto instituição monopolizadora da prestação jurisdicional - já não é capaz de lidar com a complexidade conflitiva, o debate acalorado daí resultante não vem alcançando as expectativas de diagnóstico e mapeamento dos fatores culturais causadores da crise. Desse modo, impossibilitados de romper o paradigma jurisdicional atual que, estrutural, política e culturalmente, mantém-se centralizado na figura do juiz o debate se faz polêmico, mas não alcança meios de oferecer respostas quantitativas e, principalmente, qualitativamente satisfatórias aos anseios dos jurisdicionais. Não há consenso no que concernem as causas e soluções que resultam na ineficiência estatal em uma de suas funções mais importantes: jurisdicionar.

Porém, apesar das crises, o Judiciário ainda possui o papel de protagonista no tratamento de litígios, subordinando-se à lei e dela retirando a sua existência e a sua legitimidade. Por conseguinte, os vínculos jurídicos/estatais podem ser expostos através da análise da complexidade crescente das relações e das estruturas sociais e políticas. Essas relações estão cimentadas entre si de maneira ainda precária e a isto se chama integração social fraca. Ainda, a expansão de instrumentos de controle social de caráter não jurídico, dentre eles os de tecnologia, de controle informal e de meios de comunicação de massa, redundam na necessidade de re-

\footnotetext{
3 Nesse ponto é importante dizer a que noção de crise se está fazendo referência uma vez que no cenário brasileiro atual falar em crise tornou-se um inevitável lugar comum, especialmente quando se verifica que o sólido aos poucos esmaeceu corroído pela incompatibilidade entre as complexas relações sociais e as estratégias hegemônicas atuais. Assim, o fio condutor da presente discussão tem como fundamento o fato de que uma crise não é concebida exatamente da mesma maneira em áreas diversas. Por isso, falar de crise em filosofia, em história das ciências, em medicina, em psiquiatria ou em economia são coisas diversas. Entretanto, existe um conjunto de traços comuns a toda crise, desde que se situe a análise em um nível profundo, o das estruturas na maioria das vezes não aparentes, o das estruturas reais do fenômeno estudado. Por isso, “[...] a crise aparece então como um momento no qual se inicia o jogo do par de oposição continuidade/ruptura [...]." (ARNAUD, 1991. p. 171).
} 
organização da justiça que vai além do simples reaparelhamento estatal, passando pela participação popular na sua administração, na abertura do Judiciário, a formas legítimas e razoáveis de democratização, revendo o papel dos juristas.

Entretanto, não se pode falar do Poder Judiciário como uma instituição descartável. De fato, ele passa por uma crise que também é a crise do Estado e do Direito, mas não pode ser dispensado ${ }^{4}$. Novas estratégias de atuação da função jurisdicional precisam ser criadas para que o cidadão volte a crer na justiça, existindo, para tanto, algumas razões importantes: a primeira é a de que uma sociedade complexa não pode dispensar um sistema de regras e, consequentemente, uma jurisdição que garanta o seu respeito ou sanção (nos casos de infração). Além disso, renunciar à justiça não é possível sob pena de uma outra vez se ver instalada a guerra de todos contra todos no mais típico Estado de natureza. Frente às dificuldades de funcionamento do Judiciário, o que se pretende é rever a atuação do mesmo na busca de respostas adequadas aos conflitos sociais.

Assim, o presente texto tem por objetivos: a) primeiramente discutir o papel do sistema Judiciário como meio legitimado a punir condutas racionalizando a violência; b) posteriormente os contornos da função de decidir atribuída aos magistrados serão investigados. Isso ocorrerá uti-

4 A mesma crise que enfrenta o Direito e o Judiciário brasileiros é a crise que atravessam muitos países da Europa, dentre eles a Itália, e nem por isso o Judiciário lá, como aqui, tornou-se uma instituição descartável. Nesse sentido: “Anzitutto, la situazione della giustizia civile italiana presenta un tasso di concentrazione delle controversie avanti al giudice ordinario assai superiore a quello degli altri paesi, anche dell'Europa continentale [...] Di altra natura sono i problemi connessi con la struttura burocratica dell'amministrazione della giustizia e col sistema di reclutamento dei magistrati. Detto in strema sintesi, questo sistema si traduce nell'affidamento delle cause in primo grado prevalentemente a magistrati che si trovano nella fase iniziale della carriera, e quindi in età media intorno ai trenta-trentacinque anni, poiché il progredire nella carriera stessa significa il passaggio alle funzioni di giudice di appello prima e giudice di cassazione poi.[...] Non si tratta, ovviamente, di un problema di riguardi soltanto il giudizio di primo grado. Di autorevolezza manca la giustizia d'appello e manca - ciò che per aspetti è più grave - la giustizia di cassazione [...]." (DENTI, 1987. p. 66-68). 
lizando-se das intersecções entre direito e literatura ${ }^{5}$, abordando o texto "As Vespas" de Aristófanes (2004).

Para fins de cumprir com tais objetivos o método de abordagem utilizado foi o dedutivo (LEAL, 2007) ${ }^{6}$, partindo da relação entre argumentos gerais, denominados premissas, para argumentos particulares, até se chegar a uma conclusão. Como método de procedimento foi utilizado o método monográfico, a partir de pesquisas e fichamentos em fontes bibliográficas, estudo de estatísticas ligadas ao tema da pesquisa, além de livros e trabalhos relativos ao assunto.

Assim, o texto se organiza em três partes, sendo que a primeira teve por escopo delinear o monopólio estatal da força por parte do Estado enquanto meio legítimo de punir a violência e de dizer o direito. Num segundo momento foi abordada a jurisdição e suas crises em decidir conflitos bem como as dificuldades de implantar uma outra cultura que tenha por prioridade as formas alternativas tais como a mediação, a conciliação e a arbitragem. Por fim, o final do texto aborda o mito do juiz decisor com base na peça de teatro "As vespas" de Aristófanes.

É esse, pois, o texto que se apresenta.

\footnotetext{
5 As relações entre direito e literatura têm sido alvo de inúmeras (e férteis!) discussões. Isso se dá pelo fato de que o direito, tal como toda e qualquer experiência humana, também é "contado/narrado". A narrativa literária pode ser a mola propulsora de proveitosos debates para fins de questionar e afirmar (ou não!) os fundamentos da justiça, do direito, dos princípios jurídicos, do processo, de seu tempo e de seus ritos. Nessa perspectiva, inumeráveis obras podem ser (re)lidas com olhos transdisciplinares que busquem fundamentos na psicanálise, no direito e na literatura para fins ampliar sua compreensão sobre os homens e a justiça humana. Sobre o assunto é importante a leitura de: OST, François. Contar a lei: as fontes do imaginário jurídico. Trad. Paulo Neves. São Leopoldo: UNISINOS, 2004; BRUNER, Jerome. La fabbrica delle storie. Diritto, letteratura, vita. Roma-Bari: Laterza \& Figli Spa, 2002; COPETTI NETO, Alfredo (Org.). Direito e Literatura. Ensaios Críticos. Porto Alegre: Livraria do Advogado, 2008; RICOEUR, Paul. Tempo e narrativa. Trad. Roberto Leal Ferreira. Campinas: Papirus, t. 3, 1997; SANSONE, Arianna. Diritto e letteratura. Un'introduzione generale. Milano: Giuffrè, 2001.

6 Ver também: VENTURA, 2000.
} 


\section{O Monopólio Estatal da Força e a "Vingança Racionalizada": o Judiciário como instância legitimada a tratar conflitos}

Com o intuito de pacificar a sociedade, o Estado toma para si o monopólio da força legítima, alçando pelo direito de decidir litígios e evitar/ aplacar/punir a violência através de um sistema diverso do religioso e do sacrifical $^{7}$, denominado Sistema Judiciário. O poder de tal sistema de evitar/aplacar/punir a violência se diferencia de seus outros atributos porque não é ao culpado que se voltam os olhos, mas à vítima não vingada, sendo preciso dar a ela uma satisfação meticulosamente calculada, para apagar definitivamente os seus desejos de vingança, evitando a todo custo que sejam acesos novamente. Não se trata de legislar a propósito do bem ou do mal, não se trata de fazer respeitar uma justiça abstrata, se trata de preservar a segurança do grupo afastando a vingança, de preferência com uma reconciliação baseada na composição ou em qualquer outra forma que dê resultados, de modo que a violência não volte a ocorrer. $\mathrm{O}$ encontro entre culpado e vítima se desenvolverá em campo fechado, de forma regulada e entre adversários bem determinados (GIRARD, 2005).

Em contraposição a essa ideia é que nasce na Europa o "princípio da não violência" cuja expressão por si só suscita múltiplos equívocos, mal-entendidos e confusões. Talvez isso ocorra porque desde logo a ex-

\footnotetext{
7 Sobre o assunto, é de grande importância a obra de Renè Girard (2005), na qual ele demonstra como o sacrifício possibilitava o distanciamento da violência, interpretando-o como violência substitutiva, reconhecendo em seu âmago uma verdadeira operação de transferência coletiva que se efetua às expensas da vítima e que investe as tensões internas, os rancores, a rivalidade, todas as agressões no seio da comunidade. Ao conceituar sacrifício o autor afirma: "[...] o sacrifício apresenta-se de duas maneiras opostas: ou como "algo muito sagrado", do qual não seria possível abster-se sem negligência grave, ou, ao contrário, como uma espécie de crime, impossível de ser cometido sem expor-se a riscos igualmente graves. [...] Há um mistério do sacrifício. As piedades do humanismo clássico adormecem nossa curiosidade, mas a familiaridade com antigos autores desperta-a. Hoje, o mistério continua tão impenetrável quanto sempre. Na maneira com a qual os modernos o manejam não se sabe o que predomina: se a indiferença, a distração, ou uma espécie de secreta prudência. Há aqui um segundo mistério, ou ele é o mesmo? Por que, por exemplo, ninguém se pergunta sobre as relações entre o sacrifício e a violência?" (GIRARD, 2005, p. 13).
} 
pressão delineia uma negação, uma oposição, uma recusa. Assim, a palavra alimenta inúmeras ambiguidades. Porém,

[...] só será possível determinar o significado da não-violência se tivermos previamente determinado o significado da violência. Importa determinar a que exatamente a não-violência diz não, a que é que ela se opõe, aquilo que ela recusa (MULLER, 1995, p. 15-16).

Para que se entenda melhor a busca pela não-violência e a maneira atual de tratar dos conflitos, seja oficial (Judiciário) ou inoficial (violência privada), é importante distinguir entre situação polêmica e Estado agonal. A primeira é refletida na violência aberta e direta. É uma situação conflitiva ou que corre o risco de chegar a sê-lo, pouco importando o grau de violência. A característica essencial da situação polêmica é que os opositores se enfrentam como inimigos ${ }^{8}$, o que quer dizer que se dão, mutuamente, o direito de se suprimir fisicamente. Já "o Estado agonal consiste naquela situação que logrou desativar os conflitos e substituí-los por outra forma de rivalidade, conhecida pelo nome de competição" (FREUND, 1995, p. 66-76). Nesses termos, se assimila ao jogo.

[...] A característica essencial é que os rivais não se comportam como inimigos, e sim como adversários ${ }^{9}$, o que quer dizer que de

8 Eligio Resta (2005, p. 97) define "inimigo" como aquele "[...] che indica uno stato di inimicizia, diversa dal non essere amico, che si colloca, o è collocato fuori non si sa da cosa, ma sempre all'esterno di un interno: da un gruppo, da una comunità, da uno Stato, da una nazione. Egli è sempre fuori da qualcosa che blinda i suoi confini più o meno immaginari giustificandoli con qualche cogente necessità imposta da una geografia, da una politica o da una cultura, se non da un semplice stato d'animo. Il nemico quando viene identificato, serve persino a rafforzare i confini di un inside, di un territorio qualsiasi e di qualsiasi natura che conserverà sempre la caratteristica di un Nomos der Erde segnato dall'appropriazione di una terra $[\ldots]$ "..

9 Giovanni Cosi (2004, p. 23) diferencia adversário de inimigo salientando: "L'avversario è infatti colui senza il quale, nel conflitto, io non esisto: solo dove lui è, anch'io posso veramente essere. Con lui ci si confronta. L'avversario mi permette infatti non solo di misurarmi con lui, ma anche con me stesso: mi fa scoprire i miei limiti le mie possibilità. L'avversario è come me: ha i miei stessi timore e le mie stesse speranze; imparando a conoscerlo, scoprendo la sua forza e le sue ragioni, i suoi punti deboli e le sue incongruenze, imparo a conoscere anche i miei. Perciò gli devo rispetto. Il nemico 
antemão a violência e a intenção hostil estão excluídas, ainda que permaneça a possibilidade de vitória ou de queda frente ao outro competidor (FREUND, 1995, p. 66-76).

No Estado agonal, os meios de jogar são definidos de antemão, sendo que ambos os competidores renunciam ao ataque da integridade física recíproca. Os meios de definir tais regras circulam desde o estabelecimento de instituições até a criação do Direito. Tais regras servem para impor condutas e proibições aos rivais, bem como determinar as condições de vitória. Em resumo, o Estado agonal é o fundador de uma ordem reconhecida por todos, que não está na vontade discricionária do vencedor, como ocorre ao acabar um conflito violento. No entanto, a estabilidade do Estado agonal é precária, podendo sofrer abalos. Na tentativa de manter a ordem a qualquer custo, muitas vezes se lança mão do uso abusivo da coerção, fazendo da mesma um instrumento de opressão.

Nesses termos, o Estado agonal objetiva a submissão da vida à regulamentação e ao Direito ${ }^{10}$. É conhecido como o "Estado dos juízes", pois busca no procedimento judicial a solução de rivalidades e de divergências políticas. Contudo, as dúvidas nascem da incerteza de que a instauração do Estado agonal seja sempre desejável, temendo que ele

[...] possa determinar um conservadorismo social ao impor regras de flexibilidade e plasticidade rígidas que não atendam à complexidade social na qual estão inseridas (HAMPSHIRE, 2000, p. 75-76).

Desse modo, a missão precípua do Estado é estabelecer, manter e, se for o caso, restabelecer a paz civil, objetivando garantir a segurança dos cidadãos. Então, a ordem pública nasce como resultado de uma organização constrangedora da sociedade, calcada em obrigações e interditos. O Estado, por sua vez, arroga para si e exerce um poder de coação sobre

è invece colui che mi impedisce di esistere: dove lui è, io non posso essere. Con lui si combatte; fino alla resa, o all'annientamento [...]".

10 "Il dominio, la repressione dei conflitti con la forza o con la minaccia del ricorso alla forza, è un grande male politico che ogni cittadino dovrebbe sentire come tale, anche se non condivide la posizione di altri cittadini che riconoscono a esso una particolare priorità rispetto ai grandi mali" (HAMPSHIRE, 2000, p. 64). 
todos os cidadãos. Isso se dá porque é ilusório pretender gerar uma sociedade segura e igualitária recorrendo apenas aos meios de persuasão ${ }^{11}$; assim, os meios de coação servem para obrigar os indivíduos a respeitarem o "contrato social ${ }^{12}$ " que funda a ordem e a coesão da cidade.

Então, percebe-se a existência de

[...] um direito e de um dever de defesa da sociedade contra aqueles que perturbam a ordem pública. Uma sociedade de direito não pode passar sem uma justiça e uma polícia institucionalizadas, capazes de "pôr fora de combate", isto é, de neutralizar pela "força pública", os indivíduos e os grupos que põem em perigo a paz civil. Portanto, não poderíamos organizar uma sociedade de justiça e de liberdade sem reconhecer a legitimidade da obrigação da lei e da coação da justiça (MULLER, 1995, p. 123).

Diante de tais fatos a questão é: se a coação social e o uso da "força pública" são necessários para assegurar a paz civil, quais são os meios legítimos dessa coação? Os Estados respondem a essa pergunta reivindicando o monopólio da violência legítima baseada na teoria weberiana de legitimação. Em resumo, a coação e a violência são os meios específicos estatais de fazer valer as leis e os pactos entre os cidadãos. Fica evidente que existe uma relação orgânica entre o Estado e a violência, cujo elo é irredutível e constitutivo da instituição estatal.

Essa coação se dá principalmente pelo Judiciário que protege direitos e garante o cumprimento das leis aplicando sanções aos infratores. No momento em que o Sistema Judiciário (ou Estado agonal, como quer Freund) passa a reinar absoluto como único meio de impor regras de tratamento de conflitos, dissimula - e ao mesmo tempo revela - a mesma vingança avistada nos sacrifícios religiosos, diferenciando-se somente pelo fato de que a vingança judicial não será seguida de outra, rompendo,

11 Essa ideia de sociedade pacífica e segura sem coação pode ser ilustrada pela sociedade sem classes da teoria marxista.

12 Nos exatos termos da teoria hobbesiana. 
assim, a cadeia vingativa ${ }^{13}$. Desse modo, o Poder Judiciário racionaliza a vingança, a subdivide e a limita como melhor lhe parece e a manipula sem perigo; buscando uma técnica eficaz de prevenção da violência. Essa “[...] racionalização da vingança se apoia sobre a independência da autoridade judiciária que recebeu tal encargo, atribuição que ninguém discute" (GIRARD, 2005, p. 40-41). Assim, o Judiciário não depende de ninguém em particular, é um serviço de todos e todos se inclinam diante de suas decisões.

Somente ao Poder Judiciário se atribui o direito de punir a violência porque possui sobre ela um monopólio absoluto. Graças a esse monopólio, consegue sufocar a vingança, assim como exasperá-la, estendê-la, multiplicá-la. Nesses termos, o sistema sacrifical e o Judiciário possuem a mesma função, porém o segundo se mostra mais eficaz, desde que associado a um poder político forte. Todavia, ao delegar a tarefa de tratamento dos conflitos ao Poder Judiciário - num perfeito modelo hobbesiano de transferência de direitos e de prerrogativas - o cidadão ganha, de um lado, a tranquilidade de deter a vingança e a violência privada/ilegítima para se submeter à vingança e à violência legítima/estatal, mas perde, por outro, a possibilidade de tratar seus conflitos de modo mais autônomo e não violento, através de outras estratégias.

É nesse sentido que a não-violência postula uma transformação profunda e constante do Estado. Contudo, adotar a não violência não significa o desaparecimento de todo o poder político de coação. Querer construir uma sociedade sem governo, sem leis, sem polícia e sem justiça, é uma utopia. Assim como é utópico sonhar com uma sociedade sem conflitos.

Também o projecto de sociedade que se inspira na filosofia da não-violência visa instituir um poder político de regulação, de coordenação, de mediação, de arbitragem e, se for o caso disso, de coacção, que seja um 'equivalente funcional' do Estado, mas que nos

13 Por isso, segundo Eligio Resta (2005), é confiado ao mecanismo judiciário não o exercício da virtude, mas a difícil tarefa de dizer a última palavra sobre os conflitos e, graças a isso, minimizar a violência, evitando o seu perpetuar. Depurada da retórica mais ou menos justificada, esta é a função que o sistema legal atribui ao juiz: interromper o conflito e decidir. 
pareça preferível não denominar assim, em nome do rigor e clareza dos conceitos. (MULLER, 1995, p. 27).

Um poder político assim, se diferencia profundamente do Estado na sua relação com a violência. Esse

[...] novo poder político em vez de suprimir os conflitos pela violência, esforçar-se-ia por assumi-los e resolvê-los pela não-violência. Este esforço deveria enraizar-se numa vontade política tenaz e ganhar corpo em soluções técnicas suscitadas por uma vigorosa inventividade institucional. Estas não se poderiam encontrar num qualquer manual teórico; deveriam ser implementadas progressivamente através de múltiplas experiências sociais que não seriam conduzidas à margem da sociedade, mas constituiriam um investimento institucional prioritário. (MULLER, 1995, p. 123).

Esse investimento em um outro paradigma para a resolução de conflitos poderia romper com o modo atualmente utilizado apostando numa matriz consensuada e autonomizadora, cujos consensos construídos pelas próprias partes poderiam ser melhor aceitos e cumpridos.

\section{O Judiciário em um Contexto de Crise: a busca por outra cul- tura no tratamento dos conflitos}

Enquanto a cultura da não violência não se concretiza, não ganha corpo e adesões, a sociedade atual permanece inerte esperando que suas contendas sejam decididas pelo juiz ${ }^{14}$. Da mesma forma como o cidadão de outrora que esperava pelo Leviatã para que ele fizesse a guerra em busca da paz, resolvesse os litígios e trouxesse segurança ao encerrar a

\footnotetext{
14 "La nostra cultura appartiene da tempo al gruppo di quelle che hanno deciso di delegare prevalentemente al diritto statale e ai suoi strumenti formali di decisione delle controversie la gestione dei conflitti sociali. Non importa se di civil o di common law, se accusatori o inquisitori, i nostri sistemi giuridici ci sembrano i soli capaci di garantire un livello accettabile di ordine e sicurezza, scongiurando al tempo stesso la necessità di ricorrere a interventi di controllo eccessivamente repressivi, se non addirittura totalitari [...].” (COSI, 2004, p. 21).
} 
luta de todos contra todos, atualmente vemos o tratamento e a regulação dos litígios serem transferidos ao Judiciário, esquecidos de que o

[...] conflito é um mecanismo complexo que deriva da multiplicidade dos fatores, que nem sempre estão definidos na sua regulamentação; portanto, não é só normatividade e decisão (RESTA, 2005, p. 74-75).

Unidos pelo conflito, os litigantes esperam por um terceiro que o "solucione". Espera-se pelo Judiciário para que diga quem tem mais direitos, mais razão ou quem é o vencedor da contenda. Trata-se de uma transferência de prerrogativas que, ao criar "muros normativos", engessa a solução da lide em prol da segurança, ignorando que a reinvenção cotidiana e a abertura de novos caminhos são inerentes a um tratamento democrático.

Essa transferência de responsabilidades quanto à gestão do conflito se direciona ao juiz que a traduz na linguagem dele ${ }^{15}$. Desse modo, partindo do processo de racionalização weberiana, o Estado, ao deter a forma de poder legal, detém, também, o monopólio legítimo da decisão vinculante. As atenções continuam centradas na figura do juiz, do qual se espera a última palavra, "não importa qual, mas a última". O lugar do juiz entre os conflitantes é uma questão complicada, uma vez que ele não se deixa encerrar na fácil fórmula da lei que assegura "distância de segurança" das razões de um e do outro. Ele vive no conflito e do conflito que ele decide, pronunciando a última palavra. Entretanto, um

[...] Sistema Judiciário chamado a decidir sobre tudo e com poderes muitas vezes discricionários e pouco controláveis, é o lugar que

15 Isso se dá, segundo Maurice Blanchot (1996), porque o juiz tem o direito de ser único maître du language. A expressão maître du language é decisiva e densa, como pode ser aquela de um pensador como Maurice Blanchot, que trabalhou de maneira muito convincente sobre o poder da escrita e sobre a ideia de comunidade. A conexão entre linguagem e comunidade não é, obviamente, imprevista, mas encontrar ligações e mediações através do juiz abre caminhos insuspeitos por meio dos quais se descobre que a linguagem da comunidade não corresponde nunca à comunidade de linguagem (BLANCHOT, 1996). 
oculta quotas fortes de irresponsabilidade: consente álibis e cobre a aguda diferença entre aquilo que o sistema da jurisdição diz que é, e o que faz, e aquilo que na realidade é e faz (RESTA, 2005, p. 65-66).

Assim, observa-se uma oferta monopolista de justiça incorporada ao sistema da jurisdição, delegado a receber e a regular uma conflitualidade crescente. Atualmente, chamamos essa conflitualidade crescente de explosão da litigiosidade, que tem muitas causas, mas que nunca foi analisada de forma mais profunda. É notório como a estrutura jurídicopolítica foi sempre muito atenta aos "remédios" e quase nunca às causas, deixando de lado análises mais profundas sobre a litigiosidade crescente, que é constantemente "traduzida" na linguagem jurídica e que se dirige à jurisdição sob a forma irrefreável de procedimentos judiciários ${ }^{16}$.

A explosão de litigiosidade se dá quanto à quantidade e à qualidade das lides que batem às portas do Poder Judiciário, especialmente observando a existência de uma cultura do conflito. Em face de tal fato, a direção da política do Direito deve ser no sentido de uma "jurisdição mínima", contra uma jurisdição ineficaz.

Quando se litiga judicialmente,

[...] ao juiz pede-se que "decida", que diga a última palavra com base na lei, e não que desenvolva a tarefa de cimento social que compete a outros mais preparados fazer. Mas o resultado, sabe-se, é paradoxal: incorpora-se no interior das competências judiciárias cada gênero de linguagem "funcional", embocando, obviamente, em uma estrada errada. Os sintomas da inadequação de tais condições são percebidos de modo incisivo. (RESTA, 2005, p. 69).

No entanto, por que não cabe ao Poder Judiciário "eliminar" e sim "decidir" conflitos sociais? O fato de que o Judiciário tem como "função

\footnotetext{
16 "Dunque il compito del giudice, fuori da ogni retorica, è quello di assumere decisioni sulla base di decisioni e di permettere decisioni sulla base delle stesse decisioni. Paradossalmente, però, in un sistema ad altissima complessità, più si decide e più aumenta il bisogno di decisione dato il carattere di rete interrelata dei sistemi di comunicazione [...]." (RESTA, 2005, p. 40).
} 
fundamental" a decisão de conflitos não quer dizer que a sua função seja a eliminação de conflitos. Assim, o conflito social representa um antagonismo estrutural entre elementos de uma relação social que, embora antagônicos, são estruturalmente vinculados - aliás, o "vínculo" é condição sine qua non do conflito. Portanto, se os elementos não são estruturalmente ligados, também não podem ser conflituosos ou divergentes. Nesse contexto, as funções (competências) do Poder Judiciário fixam-se nos limites de sua capacidade para absorver e decidir conflitos, ultrapassando os próprios limites estruturais das relações sociais. Não compete ao Poder Judiciário eliminar vínculos existentes entre os elementos - ou unidades da relação social, a ele caberá, mediante suas decisões, interpretar diversificadamente este vínculo; podendo, inclusive, dar-lhe uma nova dimensão jurídica (no sentido jurisprudencial), mas “não lhe 'compete' dissolvê-lo (no sentido de eliminá-lo), isso porque estaria suprimindo a sua própria fonte ou impedindo o seu meio ambiente de fornecer-lhe determinados inputs (demandas)" (BASTOS, 2001, p. 103).

Pormenorizando, é possível afirmar que a vida social gera as suas próprias relações. Se em qualquer uma destas relações sociais nascer um conflito e uma decisão sobre o mesmo for demandada ao Judiciário, este poderá dar uma sentença sobre aquele tipo especial de relação social. Por conseguinte, não é pelo fato do Judiciário decidir a respeito de divórcio ou separação, de uma ação de despejo ou homologar um dissídio coletivo entre patrões e empregados, que deixarão de existir vínculos familiares ou trabalhistas, convergentes ou divergentes ${ }^{17}$.

Consequentemente, o Judiciário funcionaliza (no sentido de que institucionaliza) ou processa conflitos sociais, mas suas decisões não eliminam relações sociais. Na verdade, ele decide sobre aquela relação so-

17 "La pace assicurata dal diritto si dimostra spesso carente sia sul piano etico che su quello pratico dell'effetiva risoluzione del conflitto perché, come già si diceva, essa segue a una procedura che di fatto tende ad assimilare i contendenti più alla figura del nemico che non a quella dell'avversario. La pacificazione giuridica non farebbe del resto che riflettere, nei metodi utilizzati e nei risultati perseguiti, il modo tipicamente competitivo d'intendere le relazioni sociali diffuso nelle moderne società tecnologicamente avanzate: no esistono altri esiti possibili di una disputa, oltre la vittoria/sconfitta e il compromesso [...].” (COSI, 2004, p. 26). 
cial especificamente demandada, o que não impede, todavia, que outras tantas, com novas características, se manifestem ou que continue existindo a própria relação social enquanto relação social. O ato do Poder Judiciário interrompe apenas aquela relação conflitiva, mas não impede o desenvolvimento de outras tantas. Não cabe ao Judiciário eliminar o próprio manancial de conflitos sociais, mas sobre eles decidir, se lhe for demandado. Assim, ele funcionaliza os conflitos sociais, mas não a própria vida. "O que se espera é que decida os conflitos que absorve, dados os graves riscos para a sua funcionalidade e para a própria sociedade" (BASTOS, 2001, p. 104).

\section{O Direito, a Literatura, o Mito e o Juiz: construções em torno do verbo "decidir"}

Como destinatário e membro representativo desse Poder Judiciário, a quem todos os conflitos são transferidos no anseio e na espera de uma solução dada e imposta, encontra-se o juiz. Figura que recebe a legitimidade de uma sociedade - e do Estado - como representante dessa soberania jurisdicional, no qual recaem inúmeras proclamações e mitos culturais, sendo "[...] transfigurado como ser diferenciado, autoridade incontrastável provida de todos os poderes, poupado ao risco de errar e revestido de tonalidade demiúrgicas" (NALINI, 2008, p. 99).

Isso acontece porque se criou verdadeiro mito ${ }^{18} \mathrm{em}$ torno da figura do juiz ${ }^{19}$, sendo este a expressão e representação suprema da soberania es-

\footnotetext{
18 Quando o assunto diz respeito a mitos é possível observar que sua noção circula largamente na cultura atual. Tal pode-se ler na obra de Roland Barthes (1994) da qual nasceu tendência geral de analisar em termos de mitologia a cultura de massa e os seus produtos. Já o texto de Claude Lévi-Strauss trata dos mitos e de suas associações com a ideologia política. Sobre o assunto ver também: VATTIMO, 2007. p. 42 e ss.

19 Egresso de uma formação jurídica tradicional, dogmática e arcaica, o bacharel conviveu com proclamações do tipo "o juiz é expressão da soberania estatal”, "ordem judicial é para ser cumprida, não discutida", "o juiz pode tudo, até fazer preto do branco ou do quadrado, redondo" e outras semelhantes. Enunciados tais fazem da carreira de juiz um verdadeiro mito. Por que mito? "Entre todos os fenômenos da cultura humana, o mito é um dos mais refratários a uma análise meramente lógica”. Explica-se: o mito sugere
} 
tatal. Ao contrário do pensamento científico, o mito não é um pensamento demonstrativo, analítico, etc. Ele é narrativo, envolvendo emoções, e globalmente, com menor ou nenhuma pretensão de objetividade. Tem relação com a religião e a arte, com o rito e a magia (e aqui, de uma maneira circular voltamos a trabalhar com os argumentos de René Girard e Jean-Marie Muller), a ciência nasce, como uma oposição ao mito, como uma "desmistificação", como um “desencanto do mundo". Assim,

[...] muito antes do mundo se apresentar a nossa consciência como um complexo de coisas empíricas e de propriedades empíricas, ele se apresentou como um complexo de potências e de ações místicas (VATTIMO, 2007, p. 44).

Seguindo a teoria do mito enquanto um complexo de ações transmitidas pela narrativa, pela religião, pela arte dentre outras, Nalini (2008) observa com extrema propriedade o mito que se firmou em torno da carreira da judicatura e da figura do juiz asseverando ser impossível a humanidade viver sem esse complexo mitológico ${ }^{20}$. Aduz que "[...] o mito reflete uma conotação heróica. Auxilia na fantasia de superação das adversidades. Nítida a sua intimidade com a esperança" (NALINI, 2008, p. 99). E conclui que

[...] no mundo das incertezas e das vicissitudes, a figura do juiz representaria a última trincheira. Quando tudo o mais falhasse, have-

um puro caos, massa informe de ideias incoerentes e desafia as categorias fundamentais do pensamento. Mas na verdade: a humanidade vive sobre mitos. Numa palavra: o mito está profundamente arraigado na natureza humana e se baseia num instinto fundamental e irresistível, pois também sempre tem um fundamentum in re, sempre se refere a uma certa 'realidade'. (NALINI, 2008, p. 97-98).

${ }^{20}$ Sobre os mitos construídos em torno do mundo do direito e de seu "senso comum teórico" é importante a leitura de Luis Alberto Warat (2010, p. 67) que assume a postura de "caçador de mitos" salientando que "[...] o que sempre me motivou a caça é poder descobrir se havia entre os juristas a possibilidade de outra linguagem possível, que recuperasse a sexualidade perdida, que está na origem de toda linguagem; que pode regular as relações entre os homens fundamentadas no amor e não na coerção, recordando que a lei do desejo não está motivada pela coerção; que pode servir para recorrer aos caminhos da emancipação; que pode ser o habitat de uma intimidade não invadida [...].”. 
ria um juiz para permitir ao injustiçado repetir - Ainda há juízes em Berlim [...] (NALINI, 2008, p. 99).

Efetivamente o desenvolvimento cultural da nossa sociedade nos levou a uma quase inércia em resolver nossos próprios problemas. Litigar passou a ser associado ao pleno exercício de cidadania de um povo, que se encontra acobertado e seguro pelo manto do Estado-juiz. Em razão disso, nasceu a ideia (o mito) de que o juiz dá conta de todos os problemas, que o Poder Judiciário encontra-se de portas abertas para o litígio de sorte que todos que demandarem encontrarão nele a resposta de seus anseios de justiça.

O fortalecimento desse mito encontra respaldo nos próprios cursos de Direito de todo o País que abordam como única forma (ou, pelo menos, como a forma mais legítima) de resolução de conflitos o processo judicial. Poucos se dedicam a estudar as formas ditas alternativas, evitando sempre enaltecer a composição e a pacificação do conflito.

Nesse contexto, Nalini (2008, p. 99) explica que

[...] a cada vez que alguém pretenda fazer valer um interesse, precisará recorrer ao Judiciário. [...] O profissional encarregado de reconstituir a ordem e afastar o dano é o juiz. Em torno disso produziu-se densa tonelagem de tratados.

A figura do juiz, envolto em todos esses mitos, já foi objeto de análise em uma obra intitulada "As Vespas", peça teatral de autoria do grego Aristófanes estreada em 422 a.C. A obra é uma sátira produzida em volta do Sistema Judiciário grego da época e que identifica o desencanto com o modelo Judiciário ateniense.

Mário da Gama Kury (prefácio, ARISTÓFANES, 2004, p. 17-18), que traduziu a comédia para o português, resume o enredo da seguinte forma:

Filoclêon (que significa 'amigo de Clêon', orador, general, político controvertido, demagogo corrupto) é fanático pelas sessões do tribunal. Seu filho Bdeliclêon ('inimigo de Cléon') tenta curá- 
-lo de sua mania judicatória e, como último recurso, segrega-o em sua própria casa. Os componentes do coro (velhos jurados como Filoclêon) chegam em frente à sua casa, fantasiados de vespas, antes do amanhecer para levá-lo com eles ao Tribunal, e o ajudam como podem em sua tentativa de escapar da 'prisão domiciliar' a que o filho o sujeita. Há uma escaramuça entre os jurados e os escravos de Bdeliclêon, seguindo-se uma discussão entre Filoclêon e Bdeliclêon quanto aos méritos e defeitos da instituição do júri, na qual Filoclêon a defende alegando os benefícios que obtém pessoalmente graças ao sistema. Rebatendo, Bdeliclêon demonstra que na realidade os jurados são meros instrumentos dos governantes, que desviam em benefício próprio o grosso da arrecadação destinada a alimentar o povo necessitado. O coro se deixa convencer e persuade Filoclêon a julgar somente os casos ocorrentes em seu próprio lar, começando pelo de Labes, o cão de guarda da casa, que furtou um queijo na despensa. Graças a um ardil do filho, Filoclêon é induzido sem perceber a absolver o criminoso, o primeiro réu que ele deixava em liberdade em toda sua longa vida de jurado. Bdeliclêon então resolve reeducar o pai para a vida social, e melhorar suas roupas e maneiras, passando a levá-lo a jantares. Os resultados são desastrosos, pois Filoclêon embriaga-se, insultando os demais convidados, pondo-se afinal à frente dos componentes do coro para dançar indecentemente.

Logo no início da comédia, em um diálogo entre dois personagens da peça, Sosias e Xantias, escravos de Filoclêon, há uma explicação sobre a "doença" que ataca Filoclêon. Diz Xantias:

[...]. Se vocês estão curiosos por saber, façam silêncio: vou dizer qual é mesmo a doença de meu senhor: é a paixão pelos tribunais. A paixão dele é julgar; ele fica desesperado se não consegue ocupar o primeiro banco dos juízes. A noite ele não goza um instante de sono. Se por acaso fecha os olhos, o próprio espírito fica olhando para a clepsidra. A paixão dele pelo voto no tribunal é tão grande que faz ele acordar apertando três de seus dedos, como se oferecesse incenso aos deuses, em dia de lua nova. [...] Logo depois do jantar ele pedia as sandálias, corria para o tribunal em plena noite e adormecia lá, colado a uma coluna como uma ostra à concha. [...] 
Com receio de não ter a pedrinha para o voto, ele tinha no jardim de sua casa um canteiro de pedrinhas, que renovava sem parar. Esta era a sua loucura. (ARISTÓFANES, 2004, p. 17-18).

A obra faz crítica aos juízes da época e a necessidade que tinham de julgar sempre. A ânsia era fruto do preço que recebiam pelo encargo, comprovando ser um rentável meio de vida para a época. Assim, o texto dá a entender que julgar além de uma fonte de poder e de projeção social também era um meio de subsistência do qual os juízes tiravam o sustento ${ }^{21}$.

Com efeito, a sátira referia-se à um caso de juiz que não julgava, apenas condenava, independente da justiça que havia na condenação. Evidencia assim o julgar de modo mecânico ${ }^{22}$, possuindo como resultado sempre a condenação, sem que houvesse análise de provas e fundamentação para as sentenças. Por conseguinte, julgar era a função e condenar a regra/resultado, sem que pudessem ocorrer variantes.

21 Várias passagens do livro contribuem para o enriquecimento da ideia satirizada por Aristófanes (2004). A necessidade de julgar de Filoclêon é exteriorizada em várias passagens, dentre as quais se podem destacar: "Você bem merece; por mim, prefiro a vida que você quer que eu abandone, em vez da maior prosperidade. Um processinho recheado é um prato que me agradaria muito mais" (ARISTÓFANES, 2004, p. 36). "Que criatura é mais feliz, mais afortunada do que um juiz? Que vida é mais gostosa do que a dele? Que animal é mais temível, principalmente na velhice?" (ARISTÓFANES, 2004, p. 38).

22 Leia-se por julgar mecânico aquele carente de reflexão e fundamentação, impulsionado apenas pela necessidade de atender a expectativas em termos de números, estatísticas, tabelas; um julgar no qual a eficiência do juiz é medida pela quantidade de suas decisões e nem sempre pela qualidade das mesmas. Exemplo desse julgar e do distanciamento cada vez maior entre o juiz e o jurisdicionado e entre a premência que se cobra do primeiro a decisão que responde ao segundo é o processo eletrônico. Sobre o assunto Alexandre Morais da Rosa (2010) se questiona: "Com isto, em breve, da velha tarefa de julgar sobrarão apenas lembranças nostálgicas? O ambiente democrático que permeava o Poder Judiciário é tomado por um totalitarismo em que, diante da 'burocratização eficiente' da atividade, pouca democracia se poderá buscar (Marco Marrafon). O tempo de um magistrado cada vez mais é tomado pelo preenchimento de infinitos relatórios de gestão, sistemas de monitoramento, coerções de uniformidade, e a consequência é que não restará, parafraseando Lebrun, nem tempo nem espaço, e sobretudo desejo para que alguns assumam, de tanto que estarão sujeitos a tarefas de controle e de gestão. Dito diretamente: Gestão sem Jurisdição". 
Em várias passagens da peça é possível extrair o prazer pessoal de Filoclêon na condenação e sua obsessão com o tribunal e com o poder que lhe é legitimado na arte de julgar. Tais conclusões são facilmente perceptíveis em diálogos como:

Que é que vocês estão querendo fazer? Vocês não vão mesmo me deixar julgar? Dracontidas vai ser absolvido! [...] O deus de Delfos me respondeu um dia que eu morreria no momento em que um acusado escapasse de minhas mãos. [e] [...] Sou mesmo um infeliz! Se eu pudesse matar você!... Mas, com quê? Depressa! Uma espada ou uma sentença condenatória! [e, ainda] Meus amigos! Estou secando de impaciência depois de ouvir vocês dessa janela, mas não posso ir cantar com vocês. Que é que vou fazer? A minha gente toma conta de mim porque estou pegando fogo para ir com vocês, juntar nossas urnas e pronunciar alguma sentença condenatória. (ARISTÓFANES, 2004, p. 19-20 e 27).

Da simples leitura da obra, fica fácil observar que existia forte tendência à condenação, sem mesmo prévio conhecimento da causa e sem nenhuma fundamentação da sentença. Nesses termos, e comparando a realidade evidenciada na peça teatral e aquela com a qual nos deparamos nos dias de hoje, sabemos que

[...] nem sempre se interpreta uma lei para fundamentar racionalmente uma decisão. E nem sempre a fundamentação e a interpretação das leis são anteriores à decisão. O que se verifica é que muitas vezes primeiro se decide e depois se ocorre a fundamentação e a interpretação (WARAT, 2010, p. 54).

Atualmente, o sujeito juiz encontra-se num dilema semelhante aquele que se avista no texto de Aristófanes. Porém suas causas são diversas: em Aristófanes, os juízes julgam porque não conseguem imaginar-se desempenhando outro papel e porque acreditam que ninguém mais saberá fazê-lo de maneira adequada (leia-se condenando). A magistratura hodierna

[...] se decide como deve decidir, com reflexão e enunciação, demora mais do que o sistema exige, e traz consigo a acusação de jul- 
gar contra o que já está estabelecido, dando falsas esperanças...; se decide como já-está-decidido apaga seu nome da decisão, a saber, não faz diferença quem assina, pois qualquer um poderia assinar essa decisão sem enunciação [...]. (ROSA, 2010).

Assim, para que o texto possa realmente basear uma reflexão sobre os contornos atuais da atividade jurisdicional é necessário, sabidamente, redimensionar o enredo e a crítica para um cenário mais contemporâneo, de modo que "As Vespas", enquanto sátira retrata um período demasiado antigo e outra realidade social. Pretendeu debater e refletir a ânsia de um grupo de juízes que não podia se distanciar do ato de julgar.

Atualmente, a necessidade/ânsia pelo julgamento encontra lugar também dentre os próprios jurisdicionados que confiam e legitimam apenas o Poder Judiciário como poder soberano, o dono da verdade suprema, que deve $e^{23}$ decidir e resolver os seus problemas. É correto afirmar que a judicatura continua representando, para a maioria, uma posição privilegiada, significado de poder e representação de uma elite, pois o juiz é um dos agentes políticos melhor remunerado pelo Estado ${ }^{24}$.

Nesse sentido, é possível observar que existem magistrados que cada vez mais se socorrem dos meios alternativos para solucionar os conflitos judiciais (mediação, conciliação) dado o acúmulo e a carga sobre-humana de trabalho e de processos. Por outro lado, existem aqueles que,

${ }^{23}$ É importante recordar aqui as lições da disciplina de Processo Civil nas quais se aprende que as partes têm o ônus de praticar os atos processuais que a elas são atribuídos. Já o juiz tem o dever de decidir, não pode se esquivar ou deixar de fazê-lo.

24 Por que o subsídio dos juízes brasileiros, após a EC 45, é um dos maiores da América Latina? Ao pensar sobre este tema cabe a advertência de Milton Friedman: não existe lanche grátis! Dito de maneira mais direta: alguma coisa se esconde por detrás desse movimento, manifestamente ideológico. No pós Constituição de 1988 o Judiciário passou a responder com maior veemência às demandas populares, especificamente no cumprimento das promessas da Modernidade, na efetivação dos Direitos Fundamentais (Lenio Streck, Ingo Sarlet). Embora não tenha sido a pretensão do próprio Poder Judiciário, no pós 1988 (Wernecj Viana), a magistratura passou a ser a alavanca de modificações estruturais, com o aumento do "custo país", a saber, a atividade econômica precisava compor o "custo da produção" com o fator Poder Judiciário, manifestado pelo binômio "previsibilidade" e "eficiência". Isto porque houve uma postura de parcela significativa da magistratura no sentido da Justiça Social. (ROSA, 2010). 
imbuídos e submersos na doença de Filoclêon, tão bem retratada nas "Vespas", resistem a todas essas estratégias imaginando que ninguém, nenhum outro "ser mortal" poderá alcançar aquilo que somente eles, juízes, sabem fazer: decidir sobre os conflitos sociais. De certa maneira, tal posicionamento reflete o medo de perder a prerrogativa de "decidir" os conflitos, a insegurança pela possível transferência de "legitimação" do seu tratamento aos próprios conflitantes e mais, a angústia pela perda de um espaço e de um poder que até então era somente deles (magistrados).

Acontece que vivenciamos (magistrados e jurisdicionados) uma forte cultura nacional de apego às regras jurisdicionais e a crença de que a justiça apenas se alcança com a prolação da sentença, imposta pelo juiz togado, invertendo-se, de certo modo, a sátira. Igual Ficloclêon, cuja necessidade de julgar era característica marcante, a maioria dos jurisdicionados apenas veem no Judiciário a concretude de seus ideais. Da mesma forma que o juiz da obra ansiava em julgar e condenar, os jurisdicionados buscam apenas a justiça advinda do juiz, baseada na sentença e na aplicação da lei, ignorando, a grande maioria, outras formas de resolução de conflitos. Como salienta Nalini (2008, p. 107), "[...] hoje, o brasileiro padece de demandismo"; poderíamos acrescentar: também padece de "medo" de resolver seus conflitos atribuindo tal tarefa a um terceiro: o juiz.

\section{Conclusões}

Efetivamente, um dos maiores obstáculos vivenciados no Brasil, especialmente no que concerne à adoção de técnicas alternativas de jurisdição (conciliação, mediação, arbitragem) está na mentalidade urdida das faculdades de Direito e arraigadas nas praxes forenses, cuja solução do problema advém do contencioso e da adjudicação dos conflitos de interesses.

Da mesma forma, alguns juízes optam pela prolação da sentença, estabelecendo "a paz do direito", ao invés de tentar conciliar as partes e alcançar a verdadeira "pacificação social". Sentenciar, não raras vezes, é mais cômodo e fácil. Assim, igual Filoclêon que ansiava condenar os acusados, sem prévio conhecimento, existe, hodiernamente, tendência a "condenar" a 
adoção de outras formas de resolução de conflitos, sem conhecê-las, julgando-as ineficazes à prestação jurisdicional e incapazes de satisfazer o anseio de justiça daqueles que sofrem turbação de seus direitos.

Contudo, apesar da crença uniforme na "cultura da sentença", é visível a crise pela qual passa a jurisdição atualmente, uma crise de eficiência e de identidade. Crise que ultrapassa a falta de estrutura e alcança a qualidade e a eficácia das decisões que, impostas pelo magistrado - terceiro que diz o direito -, nem sempre são exequíveis e em outras oportunidades não tratam o conflito de forma adequada produzindo "a paz do direito", mas não a afetiva "pacificação social". Desse modo, se torna necessária a busca por mecanismos alternativos de resposta aos conflitos sociais que possam tratá-los de forma adequada qualitativa e quantitativamente.

Esses mecanismos consensuais de tratamento de conflitos, entre eles - e principalmente - a mediação, precisam ter como escopo (além da celeridade processual, da proximidade entre o cidadão e a justiça, da informalidade e da diminuição de custos) principalmente o rompimento da barreira de caráter triádico da jurisdição tradicional (partes mediadas por um terceiro que impõe a decisão) para assumir uma postura dicotômica, na qual a resposta à demanda seja construída pelos próprios litigantes.

Almejando uma justiça mais próxima - não em termos geográficos, econômicos ou sociais, mas em termos que signifiquem autonomização e responsabilização do cidadão pelas decisões dela vertidas -, a mediação pode surgir como um salto qualitativo tratando o conflito não mais como um evento social patológico, um mal a ser curado, e sim como um fenômeno fisiológico, muitas vezes positivo. Isso significa abrir mão da lógica processual judiciária de ganhador/perdedor para trabalhar com a lógica ganhador/ganhador, que auxilia não só na busca de uma resposta consensuada para o litígio, como também na tentativa de desarmar a contenda produzindo, junto às partes, uma cultura de compromisso e participação. 


\section{Referências}

ARNAUD, André-Jean. O Direito traído pela filosofia. Trad. Wanda de Lemos Capeller e Luciano Oliveira. Porto Alegre: Sergio Antonio Fabris, 1991.

ARISTÓFANES, C. 455-375 a.C. As vespas, as aves, as rãs. Trad. do grego, introdução do grego e notas de Mário da Gama Kury. 3. ed. Rio de Janeiro: Jorge Zahar Ed., 2004.

BARTHES, Roland. Miti d'oggi. Torino: Einaudi, 1994.

BASTOS, Marco Aurélio Wander. Conflitos Sociais e Limites do Poder Judiciário. 2. ed. Rio de Janeiro: Lumen Juris, 2001.

BLANCHOT, Maurice. Pour l'amitié. Paris: Fourbis, 1996.

COSI, Giovanni. Interessi, diritti, potere. Gestione dei conflitti e mediazione. In: Ars Interpretandi. Padova: CEDAM, 2004.

DENTI, Vittorio. Riflessioni sulla crisi della giustizia civile. In:

TREVES, Renato. Crisi dello Stato e sociologia del diritto. Milano: Franco Angeli, 1987.

FREUND, Julien. Sociología del conflicto. Trad. Juan Guerrero Roiz de la Parra. Madrid: Ministerio de Defensa, Secretaría General Técnica. D. L., 1995.

GIRARD, Renè. La violenza e il sacro. Trad. Ottavio Fatica e Eva Czerkl. Milano: Adelphi, 2005.

HAMPSHIRE, Stuart. Non c'è giustizia senza conflitto. Democrazia come confronto di idee. Trad. Giovanna Bettini. Milano: Feltrinelli, 2000.

LEAL, Monia. Manual de Metodologia da pesquisa para o Direito. Edunisc: Santa Cruz do Sul, 2007.

MULLER, Jean-Marie. O princípio da não-violência. Percurso filosófico. Trad. Maria Fernanda Oliveira. Lisboa: Instituto Piaget, 1995.

NALINI, José Renato. A rebelião da toga. Campinas: Millennium Editora, 2008. 
RESTA, Eligio. Il diritto fraterno. Roma-Bari: Laterza, 2005.

RICOEUR, Paul. Tempo e narrativa. Trad. Roberto Leal Ferreira. Campinas: Papirus, 1997.

ROSA, Alexandre Morais da. Franchising Judicial ou de como a magistratura perdeu a dignidade por seu trabalho vivo? Texto da palestra do Fórum Mundial de Juízes de Porto Alegre no dia 24 jan. 2010. Disponível em: $<\mathrm{http}: / /$ alexandremoraisdarosa.blogspot.com/>. Acesso em: 22 fev. 2010.

SANSONE, Arianna. Diritto e letteratura. Un'introduzione generale. Milano: Giuffrè, 2001.

VENTURA, Deisy. Monografia Jurídica: uma visão prática. Porto Alegre: Livraria do Advogado, 2000.

VATTIMO, Gianni. La società trasparente. Milão: Garzanti, 2007. WARAT, Luiz Alberto. A tua grita Dionísio! Direitos Humanos da Alteridade, Surrealismo e cartografia. Trad. Vivian Alves de Assis, Júlio César Marcelino e Alexandre Morais da Rosa. Rio de Janeiro: Lúmen Júris, 2010. 